\title{
Engagement in sport career transition planning enhances performance
}

David Lavallee

This is an Accepted Manuscript of an article published by Taylor \& Francis in the Journal of Loss and Trauma available online:

https://doi.org/10.1080/15325024.2018.1516916 


\section{Abstract}

3 Retirement from sport has the potential to be a major loss for professional athletes. Yet,

4 many athletes resist engaging in career transition planning programs prior to their

5 retirement. This research note reports the findings from an investigation on whether

6 planning for an inevitable resource loss event (i.e., retirement from professional sport)

7 can accrue gains (i.e., sporting performance). Data for this study was sourced from the

8 National Rugby League, a top-level men's professional sports league in Australasia, and

9 included 28,516 performance selection observations for 632 players over three seasons.

10 The findings demonstrated that higher levels of engagement in pre-retirement planning were positively associated with team selection, team tenure, and career tenure. Preretirement planning was also found to exert its effect on performance through the experience of career transition practitioners and the number of intervention support sessions the athletes participated in. Results are discussed in relation to conservation of resources and cognitive dissonance theories.

\section{Introduction} Retirement from sport has the potential to be a major loss for professional athletes. Past research on this topic has focused on the consequences of sport retirement and how making the transition out of sport can lead to reductions in personal (e.g., loss of sporting performance skills), material (e.g., loss of occupation), and symbolic (e.g., loss of identity) resources to which the athlete was emotionally attached (cf. Harvey, 1996). Nearly one in five elite athletes experience distressful reactions following

23 retirement from sport, and many experience feelings of loss (Grove, Lavallee, Gordon,

24 \& Harvey, 1998; Park, Tod, \& Lavallee, 2013). More recent studies have also started to 
1 examine what resources can help athletes cope with the career transition process,

2 including pre-retirement planning (Park et al., 2013). Pre-retirement intervention programs offer career and education support to

4 professional athletes during their playing careers to help them plan for their inevitable

5 transition out of sport. Although pre-retirement planning is one of the best predictors of

6 successful career transitions out of sport, many athletes elect not to engage in

7 intervention programs even when they have access to such services (North \& Lavallee,

8 2004). This resistance has been attributed to the perception that engagement in career

9 transition intervention programs while still competing could be a distraction from their

10 sport performance (Park et al., 2013; Petitpas, Danish, McKelvain, \& Murphy, 1992).

11 Cognitive dissonance, therefore, may play an important role in pre-retirement planning.

12 Cognitive dissonance theory postulates that individuals strive toward cognitive

13 consistency when a situation involves conflicting attitudes, beliefs, or behaviors. If there

14 are inconsistencies, people will make alterations in their attitudes, beliefs, or behaviors

15 to reduce psychological discomfort and restore balance in their lives (Festinger, 1957).

16 The magnitude of dissonance depends on importance or value of the attitude, belief, or

17 behavior that is dissonant, and thus influences the pressure to reduce or eliminate the

18 dissonance. As the magnitude increases, pressures to reduce dissonance and avoidance

19 from situations that generate dissonance also increase. Furthermore, when individuals

20 take actions that appear to be in conflict with their starting preferences, they experience

21 feelings of discomfort. To minimize or avoid this discomfort, people change their

22 preferences to more closely align with their actions.

23 Recent theoretical and empirical perspectives influenced by Hobfoll's (2002)

24 conservation of resources (COR) theory may also help advance knowledge in the area 
1 of retirement from sport. COR theory has been adopted previously across several

2 different sporting contexts and populations (e.g., Ford \& Gordon, 2008; Wendling,

3 Kellison, \& Sagas, 2017) but the focus has generally been on psychological stress and

4 strain. A recent trend in the literature concerning COR theory has been its extension to

5 better understand how individuals allocate and conserve resources in the context of

6 resource gains and losses. Central to COR theory is the principle that resources need to

7 be invested by people in order to protect or limit potential losses. COR theory also

8 postulates a gain paradox principle: resource loss is disproportionately more salient and

9 important than resource gain (Hobfoll, 2012). From these principles, a number of

10 relevant corollaries of the resource investment process have been proposed to help

11 understand the downstream impact of changes in resources. For example, investment

12 becomes more difficult when individuals lose resources and they become more prone to

13 further investment loss (i.e., loss spirals) under stressful conditions. On the other hand,

14 when individuals gain resources they have greater opportunities to invest and accrue

15 additional resources (i.e., recourse gain spirals). These patterns have been supported

16 through studies showing how individuals who possess resources are more capable of

17 offsetting losses, and how this serves to facilitate the acquisition of other resources

18 (Ennis, Hobfoll, \& Schroder, 2000).

Wang, Henkens, and van Solinge's (2011) resource-based dynamic model has

20 proposed resources as the central mechanism that shapes how people cope with

21 retirement from the workforce. According to this model, losses, gains, or no change in

22 resources will lead to decreasing, increasing, or stable trajectories in the retirement

23 process, respectively. Recent work by Topa and Valero (2017) has applied this model in

24 a study exploring retirees' satisfaction, depression, and actual loss of resources. Results 
1 revealed that the threat of resource loss had a positive relationship on retirement

2 satsfaction and depression levels after retirement.

While recent studies in sport have helped inform the development of pre-

4 retirement intervention programs for elite athletes around the world, little research has

5 examined the impact of the investment of resources during the career transition process.

6 Given the extant research (e.g., Topa \& Valero, 2017), an interesting line of enquiry

7 would involve studying whether planning for an inevitable resource loss event (i.e.,

8 retirement from sport) can accrue gains. Such an extension of COR theory may

9 contribute to news ways of testing the resource investment process (Hobfoll,

10 Halbesleben, Neveu, \& Westman 2018). Therefore, the aim of this research was to

11 examine whether engaging in a pre-retirement planning program can enhance sporting

12 performance.

\section{Method}

Anonymized data for this study was sourced from the National Rugby League

(NRL), a top-level men's professional sports league in Australasia. A total of 16 teams

16 play in the NRL, fifteen of which are based in Australia and one in New Zealand. The

17 NRL operates on a single group system, with no divisions or conferences and no

18 relegation and promotion from other leagues. Each team plays 26 games per season

19 between March and October annually, with additional games scheduled in the finals

20 (i.e., playoffs) rounds. A total 17 players are selected to play per team for each game

21 based on performance levels at the time of selection.

Performance data was sourced across three seasons (2014, 2015, and 2016) from

23 official NRL databases, with all performance data entered manually and double-checked

24 for quality assurance purposes. Performance data included team selection, team tenure, 
1 and career tenure for each player for each game across all three years (final round

2 games were excluded because every team was not represented). The players selected for

3 each team for every potential game, taking into account availability for selection and

4 excluding injured, suspended, and players being rested, were initially coded. The

5 number of years each player had been contracted at their current club (team tenure) and

6 playing in the NRL overall (career tenure) as at the start of the season in question were

7 also recorded.

8

Pre-retirement planning data was sourced for each player and included an engagement in pre-retirement planning measure at every team selection point. Engagement in pre-retirement planning was determined through a measurement of Career Decidedness (Gordon, 1998) and Career Planning (Prochaska \& DiClemente, 1992). Career Decidedness was applied with three categories as follows: Undecided: "I don't know what I want to do after footy"; Exploring Options: "I have an idea of what I want to do/a few interests but I'm not sure yet which I really want to do after footy"; and Decided: “I'm confident I've made a well-informed choice about what I want to do after footy”. Career Planning was applied with five stages adapted from the transtheoretical model of behavior change as follows: Pre-contemplation: no thought of or intention to do career planning; Contemplation: weighing up the pros and cons of career planning, but still doing no planning; Preparation: engaging in career planning; Action: taking action towards their future career (e.g., studying, working); and Maintenance: future career has been underway for at least three months (e.g. own business, a trade, property development). For someone to be engaged they were categorised as: Exploring Options or Decided in the area of Career Decidedness; and Action or Maintenance in the area of Career Planning. Career transition practitioners 
1 (i.e., career coaches) assessed Career Decidedness and Career Planning measures for

2 every player at every team selection point, and entered the data into a software system

3 built for tracking, reporting, and case management.

Data was also sourced on the experience of the career coaches (20 in total,

5 including at least one for each team; categorized as experienced, novice, or no

6 experience) and the number of pre-retirement intervention support sessions for each

7 player $($ Mean $=1.63, \mathrm{SD}=.84)$.

8

9

\section{Results}

The data set included a total of 28,516 performance selection observations for 632 players (Mean age in $2016=23.84, \mathrm{SD}=4.26$; Mean years team tenure in $2016=$ $2.52, \mathrm{SD}=3.02$; Mean years career tenure in $2016=4.02, \mathrm{SD}=4.01)$. Engagement in pre-retirement planning was found to be significantly correlated with each of the performance measures: team selection $\left(\mathrm{X}^{2}=112.18, \mathrm{p}<.01\right)$; team tenure $\left(\mathrm{r}_{\mathrm{b}}=.48, \mathrm{p}<\right.$ $.01)$; and career tenure $\left(\mathrm{r}_{\mathrm{b}}=.52, \mathrm{p}<.01\right)$. Engagement in pre-retirement planning was also found to be significantly correlated with the number of pre-retirement intervention support sessions $\left(r_{b}=.81, p<.001\right)$ and career coach experience $\left(X^{2}=456.12, p<\right.$ $.001)$.

Linear and logistic regression analyses were also tested following relevant variable transformations. These results demonstrated that engagement in pre-retirement planning was positively associated to team selection $\left(F=6.94, p=.008, \mathrm{R}^{2}=.19\right)$, team tenure $\left(F=16.58, p<.01, \mathrm{R}^{2}=.23\right)$, and career tenure $\left(F=28.57, p<.01, \mathrm{R}^{2}=.27\right)$. Sobel tests were employed to explore whether the experience of the career coach and the number of intervention support sessions could explain the impact of pre-retirement planning on performance. Significant $(\mathrm{p}<.05)$ results were found for the experience of 
1 the career coach (team selection: $\mathrm{z}=2.21$; and team tenure: $\mathrm{z}=2.07$ ) and the number of

2 intervention support sessions (team selection: $\mathrm{z}=1.98$; and career tenure: $\mathrm{z}=3.22$ ).

3

4

5 sport can enhance sporting performance. When relationships across the study variables

6 were examined, higher levels of engagement in career transition planning were found to

7 be related to team selection when available (i.e., not injured, suspended, or being

8 rested), the number of years contracted by the team, the number of years playing

9 overall, the experience of the experience of the career coach, and the number of

10 intervention support sessions. The results support the findings by Topa and Valero

11 (2017) as the threat of a resource loss event can have a positive impact on pre-

12 retirement planning.

Further analyses showed how greater engagement in career transition planning predicted team selection, team tenure, and career tenure. These findings can be partially explained through cognitive dissonance theory as engaging in pre-retirement planning may have led to less cognitive dissonance, allowing for more time to focus on sporting performance. Previous research (e.g., North \& Lavallee, 2004) has shown how many athletes resist engaging in pre-retirement programs they have access to, possibly due to the perception that such engagement could be a distraction from their sporting performance (Petitpas et al., 1992). In this study, evidence was found to suggest that inconsistencies that might normally influence professional athletes to not engage in preretirement planning were altered. The value players placed on pre-retirement planning appears to be greater than the pressures to focus exclusively on sport performance (cf. Festinger, 1957), perhaps due to the experience of the career coach and number of 
1 intervention support sessions. The experience of the career coach was found to explain

2 the significant relationship between engagement in career transition planning and team

3 selection and team tenure, and the number of intervention support sessions was found to

4 explain the significant relationship between engagement in career transition planning

5 and team selection and career tenure.

$6 \quad$ By applying the process of resource loss and gain cycles among professional

7 athletes, this study extends Hobfoll's (2002) COR theory into the retirement from sport

8 context. The findings also support COR theory, as the professional athletes who took

9 action through engagement in pre-retirement planning invested resources in order to

10 limit potential losses. In line with Hobfoll's (2012) gain paradox principle, resource

11 gains would have increased in salience as loss circumstances became higher. In this

12 study, individuals were deemed to be engaged in pre-retirement planning if their levels

13 of career decidedness (i.e., exploring options or decided) and career planning (i.e.,

14 action or maintenance) were in the advanced stages. The downstream impact of changes

15 in resource investment is seen in the performance data for the individual, team, and

16 career overall. When individuals accrued resources in planning for their retirement,

17 they would have had greater opportunity to accrue additional resources through gain

18 spirals. In a similar way to Ennis et al. (2000), this would have allowed the athletes to

19 be more capable of offsetting losses and thereby jumpstarting further resource gains.

20 Future researchers should consider the role that time plays in in the dynamics of

21 resource investment. This temporal aspect can take many forms, ranging from the

22 amount of time over which resources are lost or gained, to the length of recovery

23 periods necessary to regain resources, to the specific timing that a resource becomes

24 available relative to the timing of resource loss (Hobfoll et al., 2018, p. 114). 
1 In terms of study limitations, every performance selection opportunity across the

2 three seasons was considered individually rather than in a repeated measures design.

3 Furthermore, the measurement of engagement in pre-retirement planning was assessed

4 by career practitioners with varying experience levels. Although the measurements

5 were underpinned by career-decision making theories (Gordon, 1998; Prochaska \&

6 DiClemente, 1992), it is possible that less experienced practitioners were not as accurate

7 in their assessment of career decidedness and/or career planning. The data for this study

8 also included only males in one professional sport (National Rugby League).

9 The results of this study may have implications in the delivery of career

10 transition programs for professional athletes. Many athletes experience feelings of loss

11 following retirement from sport. Athletes who are effectively supported by practitioners

12 in preparing for this resource loss event can realize a potential competitive advantage in

13 their sport. Teams can also benefit by retaining athletes in the system for longer along

14 with the sport, itself. These downstream impacts can occur when the value players place

15 on pre-retirement planning is greater than the pressures to focus exclusively on sport

16 performance. It is, therefore, important for players, sports coaches, and senior

17 administrators who may have misconceptions that engagement in pre-retirement

18 planning is time poorly spent to understand the positive benefits in relation to team

19 selection, team tenure, and career tenure.

\section{References}

Albion, M. J. (2007, September). Restoring the balance: Women's experiences of retiring from elite sport. Paper presented at the International Women's Conference,

23 Queensland, Australia. http://eprints.usq.edu.au/3447 
1 swears: How economic stress and resistance resources impact inner-city women's

2 depressive mood. American Journal of Community Psychology, 28, 149- 173.

3 doi: 10.1023/A:1005183100610

4 Festinger, L. (1957). A theory of cognitive dissonance. Stanford, CA: Stanford

5 University Press.

$6 \quad$ Ford, I.W., \& Gordon, S. (2008) Coping with sport injury: Resource loss and the

7 role of social support, Journal of Personal and Interpersonal Loss, 4, 243-256.

8 doi:10.1080/10811449908409733

9 Gordon, V. N. (1998). Career decidedness types: A literature review. The

10 Career Development Quarterly, 46, 386-403. https://doi.org/10.1002/j.2161-

$11 \quad$ 0045.1998.tb00715.x

Grove, J. R., Lavallee, D., Gordon, S., \& Harvey, J. H. (1998). Account-making:

13 a model for understanding and resolving distressful reactions to retirement from

14 sport. Sport Psychologist, 12, 52-67. doi: 10.1123/tsp.12.1.52

Harvey, J.H. (1996). Embracing their memory: Loss and the social psychology

16 of story-telling. Needham Heights, MA: Allyn \& Bacon.

Hobfoll, S.E. (2002) Social and Psychological Resources and Adaptation.

18 Review of General Psychology, 6, 307-324. http://dx.doi.org/10.1037/1089-

$19 \quad 2680.6 .4 .307$

20 Hobfoll, S.E. (2012). Conservation of resources and disaster in cultural context:

21 The caravans and passageways for resources. Psychiatry: Interpersonal and Biological

22 Processes, 75, 226-231. doi: 10.1521/psyc.2012.75.3.227

23 Hobfoll, S., Halbesleben, J., Neveu, J., \& Westman, M., (2018). Conservation of

24 resources in the organizational context: The reality of resources and their consequences. 
1 Annual Review of Organizational Psychology and Organizational Behavior, 5, 103-128.

2 doi: 10.1146/annurev-orgpsych-032117-104640

3

4

5

6

7

8

9

10

transition services in the United Kingdom. Psychology of Sport and Exercise, 5, 77-84.

doi: 10.1016/S1469-0292(02)00051-1

Park, S., Lavallee, D., \& Tod, D. (2013). Athletes' career transition out of sport: a systematic review. International Review of Sport and Exercise Psychology, 6, 22-53 doi: 10.1080/1750984X.2012.687053

Petitpas, A. , Danish, S., McKelvain, R., \& Murphy, S. (1992). A career assistance program for elite athletes. Journal of Counseling and Development, 70, 383386. doi: 10.1002/j.1556-6676.1992.tb01620.x

Prochaska, J.O., \& DiClemente, C.C. (1992). In search of the structure of change. In Y. Klar (Ed.), Self-change: Social psychological and clinical perspectives (pp. 87-114). New York: Springer.

Topa, G., and Valero, E. (2017). Preparing for retirement: how self-efficacy and resource threats contribute to retirees' satisfaction, depression, and losses. Eur. J. Work Organ. Psychol. 26, 811-827. doi: 10.1080/1359432X.2017.1375910

Wang, M., Henkens, K., \& van Solinge, H. (2011). Retirement adjustment: A review of theoretical and empirical advancements. American Psychologist, 66(3), 204213. http://dx.doi.org/10.1037/a0022414

Wendling, E., Kellison, T.B., \& Sagas, M. (2017). A conceptual examination of college athletes' role conflict Through the lens of conservation of resources theory. Quest, 70, 28-47. doi:10.1080/00336297.2017.1333437 